\title{
Study of the psychological status of mothers of autism spectrum disorder children
}

\author{
Shebna A Khader ${ }^{1}$, Suchetha S Rao ${ }^{2}$, *Nutan Kamath ${ }^{3}$ \\ Sri Lanka Journal of Child Health, 2020; 49(4): 325-328
}

\begin{abstract}
Introduction: Autism spectrum disorder (ASD) is characterised by deficits in verbal and nonverbal communication and social interaction. These children depend on lifelong parental care leading to psychological distress and economic burden on the family
\end{abstract}

Objectives: To assess the psychological status of mothers of ASD children attending the outpatient department of a South Indian tertiary care teaching hospital affiliated to Kasturba Medical College, Mangalore.

Method: A descriptive study was carried out on mothers of children diagnosed to have ASD. Mothers who had organic psychiatric problems were excluded. The symptom checklist $90 \mathrm{R}$ was used to analyse the psychopathology

Results: Thirty mothers of children with ASD were interviewed. Mean age group of the mothers was 28.4 years. Psychological assessment revealed that $20 \%$ of the mothers were normal. Depression was the most common psychopathology followed by anxiety seen in $33.3 \%$ and $30 \%$ of the mothers respectively. Anxiety was more in the mothers of male children $(p=0.045)$ and depression was the predominant psychopathology observed in mothers with first born child affected with autism $(p=0.028)$. More anxiety and depression was noted in nuclear families $(\mathrm{p}=0.005)$.

${ }^{1}$ Consultant Paediatrician, Midtown Medical Centre, Kochi, India, ${ }^{2}$ Associate Professor, Department of Paediatrics, Kasturba Medical College, Mangalore, Manipal Academy of Higher Education, Manipal Karnataka, India, ${ }^{3}$ Associate Dean and Professor of Paediatrics, Kasturba Medical College Mangalore, Manipal Academy of Higher Education, Manipal Karnataka, India

*Correspondence: nutan.kamath@manipal.edu

orcid.org/ 0000-0003-4458-3634

(Received on 30 October 2019: Accepted after revision on 23 December 2019)

The authors declare that there are no conflicts of interest

Personal funding was used for the project.

Open Access Article published under the Creative

Commons Attribution CC-BY (CC) (P) License
Conclusions: Mothers of ASD children had significant psychopathology. High level of depression and anxiety in mothers of ASD children, male child, first born child and nuclear family were significant risk factors for the psychopathology.

DOI: http://dx.doi.org/10.4038/sljch.v49i4.9262

(Key words: Autism spectrum disorder, disability and family support, mental health, mother, psychopathology)

\section{Introduction}

Autism spectrum disorder (ASD) is characterised by deficits in verbal and nonverbal communication and social interaction ${ }^{1,2}$. Comorbidities like motor deficits, seizures, catatonia, delayed self-help skills, seen frequently in ASD, are factors which impair the quality of life of person with ASD or their families ${ }^{3,4}$. Caring of a child with ASD can be challenging for parents due to extensive physical and developmental comorbidities ${ }^{5}$. Studies have reported that the families with ASD experience more stress than other children with special needs or normally developing children ${ }^{6,7}$. Most of the ASD children depend on lifelong parental care. The mother, being the primary caregiver of the child, is subjected to economic burden and psychological distress $^{8,9}$. Higher levels of anxiety and depression have been reported in mothers of ASD children than in mothers of children with normal development ${ }^{10,11}$. The psychological distress in the mother can lead to compromised child care. Emotional wellbeing helps the mother to deal with the challenges associated with ASD children ${ }^{8}$. Hence, early recognition of emotional disturbance in mothers, and providing them psychological support, results in better care of ASD children. Promoting mental health and wellbeing of individuals has been the target of the United Nations Sustainable Development Goal $3^{12}$.

\section{Objectives}

To assess the psychological status of mothers of ASD children attending the outpatient department of a South Indian tertiary care teaching hospital affiliated to Kasturba Medical College, Mangalore.

\section{Method}

A descriptive study was carried out in the hospital over a period of 18 months. Ethical approval was granted by the Institutional Ethics Committee of 
Kasturba Medical College, after which permission was obtained from the Authorities of concerned hospital for conduction of study. Mothers of children diagnosed to have ASD according to DSM-IV criteria, and who were literate in English, were included in study. ASD was diagnosed by clinical psychologists. DSM-IV criteria were used rather than DSM-V criteria because authors had earlier done a study on clinical spectrum of ASD children when DSM-IV was used and mothers of these children were recruited later for present study ${ }^{13}$. Mothers with organic psychiatric problems and mothers with social factors like separated family were excluded. Sample was selected by convenient sampling. Mothers were interviewed to collect the following demographic data: maternal age, type of family, educational qualification, occupation, gender of the child and birth order of child. These details were entered in a structured proforma. The symptom checklist 90 R (SCL 90$\mathrm{R})^{14}$, a detailed self-report questionnaire to analyse the psychopathology, was given to mothers. Principal investigator had explained about the study questionnaire to the participants and was available to answer any queries during the process of filling the questionnaire. The SCL-90R is self-symptom report inventory comprising of 90 items which adopts a five point scale (0-4) ranging from "not at all" to "extremely" to rate the distress. The SCL90R scores and interprets nine primary symptom dimensions and three global indices of distress ${ }^{14}$. Commercially available SCL90-R kit was used for the study which included SCL-90R manual, answer sheets, profile forms, worksheets and answer keys. Childhood autism rating scale (CARS) score, to quantify the severity of autism, was recorded from medical records. Collected data were coded and entered into Statistical Package for Social Sciences 11.5. Results were interpreted with frequency tables and bar charts. Statistical significance was computed using Chi-square, unpaired Student t- test, Kruskal-Wallis test, and Mann-Whitney test. $\mathrm{p}<0.05$ was considered as statistically significant.

\section{Results}

Thirty mothers of ASD children were interviewed to study the psychological impact of the condition. Mean age of the mothers was 28.4 years. Eighty percent of mothers had an educational level of graduation and above and $86.6 \%$ of mothers were from nuclear families. The psychological assessment by SCL $90-\mathrm{R}^{14}$ checklist revealed that in $20 \%$ of the mothers no psychopathology was identified. Depression was the most common psychopathology, followed by anxiety seen in $33.3 \%$ and $30 \%$ of the mothers respectively. Table 1 describes the type of psychological abnormality observed.

Table 1

Type of psychological abnormalities observed in mothers of autism spectrum disorder children

\begin{tabular}{|l|c|}
\hline \multicolumn{1}{|c|}{ Type } & Number (\%) \\
\hline No psychopathology identified & $06(20.0)$ \\
\hline Anxiety & $09(30.0)$ \\
\hline Depression & $10(33.3)$ \\
\hline Interpersonal sensitivity & $01(03.3)$ \\
\hline Obsessive compulsive disorder & $01(03.3)$ \\
\hline Paranoid reaction & $01(03.3)$ \\
\hline Phobic anxiety & $01(03.3)$ \\
\hline Psychotism & $01(03.3)$ \\
\hline
\end{tabular}

Global severity index (GSI) was used as indicator of the current level or the depth of the disorder. Value of 0.57 was considered as significant. GSI values suggested significant psychopathology and distress in $90 \%$ of the sample. The psychopathology of mothers in relation to gender, birth order, type of family and severity of autism is shown in Table 2.

Table 2

Psychopathology of mothers in relation to gender, birth order, type of family and severity of autism (n=30)

\begin{tabular}{|c|c|c|c|c|c|}
\hline Variable & $\begin{array}{c}\text { No psychopathology } \\
\text { identified }\end{array}$ & Anxiety & Depression & Others & p-value \\
\hline $\begin{array}{ll}\text { Gender } & \\
\text { Male } & \mathrm{n}(\%) \\
\text { Female } & \mathrm{n}(\%) \\
\end{array}$ & $\begin{array}{l}03(50) \\
03(50) \\
\end{array}$ & $\begin{array}{l}06(66.7) \\
03(33.3) \\
\end{array}$ & $\begin{array}{l}05(50) \\
05(50) \\
\end{array}$ & $\begin{array}{l}02(40) \\
03(60) \\
\end{array}$ & 0.045 \\
\hline \begin{tabular}{ll}
\multicolumn{2}{l}{ Birth order } \\
One & $\mathrm{n}(\%)$ \\
Two & $\mathrm{n}(\%)$ \\
Three & $\mathrm{n}(\%)$ \\
\end{tabular} & $\begin{array}{l}02(33.3) \\
03(50.0) \\
01(16.7) \\
\end{array}$ & $\begin{array}{c}06(66.7) \\
03(33.3) \\
0 \\
\end{array}$ & $\begin{array}{c}10(100) \\
0 \\
0 \\
\end{array}$ & $\begin{array}{c}05(100) \\
0 \\
0 \\
\end{array}$ & 0.028 \\
\hline \begin{tabular}{ll}
\multicolumn{2}{l}{ Type of family } \\
Nuclear & $\mathrm{n}(\%)$ \\
Joint & $\mathrm{n}(\%)$ \\
Extended & $\mathrm{n}(\%)$
\end{tabular} & $\begin{array}{l}03(50) \\
03(50) \\
0\end{array}$ & $\begin{array}{c}07(77.8) \\
0 \\
02(22.2) \\
\end{array}$ & $\begin{array}{l}09(90) \\
01(10) \\
0\end{array}$ & $\begin{array}{c}05(100) \\
0 \\
0\end{array}$ & 0.005 \\
\hline $\begin{array}{ll}\text { Childhood autism rating scale } \\
\text { Mild } & \mathrm{n}(\%) \\
\text { Moderate } & \mathrm{n}(\%) \\
\text { Severe } & \mathrm{n}(\%)\end{array}$ & $\begin{array}{c}03(50) \\
03(50) \\
0\end{array}$ & $\begin{array}{l}03(33.3) \\
03(33.3) \\
03(33.3\end{array}$ & $\begin{array}{c}0 \\
04(40) \\
06(60)\end{array}$ & $\begin{array}{c}0 \\
02(40) \\
03(60)\end{array}$ & 0.156 \\
\hline
\end{tabular}


Anxiety was more in the mothers of male children $(\mathrm{p}=0.045)$ and depression was the predominant psychopathology observed in mothers with first born child affected with autism $(\mathrm{p}=0.028)$. More anxiety and depression was noted in nuclear families $(\mathrm{p}=0.005)$. Depression was more in the mothers of children with severe autism, but was not statistically significant $(\mathrm{p}=0.156)$. Table 2 also shows the relation between childhood autism rating scale (CARS) scoring and psychopathology.

\section{Discussion}

The present study showed psychopathology in $80 \%$ mothers of ASD children. The most common finding was depression seen in $33.3 \%$ mothers. Study by Zhou et al has reported depressive symptoms and anxiety in $72.5 \%$ and $80.2 \%$ mothers, respectively ${ }^{5}$. Study by Bitiska et al has reported significant anxiety in $45 \%$ and major depression in $55 \%$ of mothers of ASD children ${ }^{15}$. Mothers of ASD children had elevated depression scores compared to the fathers as found by Olsson and Hwang ${ }^{16}$.

Data from ordinal regression model studies reported that higher anxiety and depression levels were found in mothers of children with severe $\mathrm{ASD}^{5,17}$. In the present study, even though depression was more in the mothers of children with severe ASD, results were not statistically significant. In the present study, more anxiety and depression were noticed in mothers from nuclear families compared to those from joint or extended families. Social support can be a protective factor against psychological distress in mothers of ASD children ${ }^{18}$. Education up to high school was a protective socioeconomic factor against depression in mothers of ASD in comparison to the welleducated group. More intelligent mothers will have a higher life expectation and may have difficulty in accepting the reality ${ }^{5}$.

The study had several limitations. The psychological status was evaluated by maternal self-report symptom questionnaire which can have potential bias. The psychological abnormalities found were not confirmed by conventional tests. Small sample size of the study population has limitation in generalising the study results. Our study participants included mainly educated mothers which again may be a limitation in applying the results to the community.

\section{Conclusions}

Our study revealed that mothers of children with ASD had significant psychopathology. High level of depressive symptoms and anxiety in mothers of ASD children, male child, first born child and nuclear family were significant risk factors for the psychopathology.

\section{References}

1. Consensus Statement of the Indian Academy of Pediatrics on Evaluation and Management of Autism Spectrum Disorder. Indian Pediatrics 2017; 54(5):385-93. https://doi.org/10.1007/s13312-017-11124

PMid: 28368272

2. Mpaka DM, Okitundu DL, Ndjukendi AO, N'situ AM, Kinsala SY, Mukau JE, et al. Prevalence and comorbidities of autism among children referred to the outpatient clinics for neurodevelopmental disorders. Pan African Medical Journal 2016; 25:82. https://doi.org/10.11604/pamj.2016.25.82. 4151

PMid: 28292045 PMCid: PMC5324163

3. Mahajnah $M$, Sharkia R, Shalabe H, Terkel-Dawer R, Akawi A, Zelnik N. Clinical characteristics of autism spectrum disorder in Israel: Impact of ethnic and social diversities. Biomed Research International 2015; Article ID 962093. https://doi.org/10.1155/2015/962093 PMid: 25984535 PMCid: PMC4422995

4. Lord C, Petkova E, Hus V, Gan W, Lu F, Martin DM, et al. A multisite study of the clinical diagnosis of different autism spectrum disorders. Archives of General Psychiatry 2012; 69(3):306-13. https://doi.org/10.1001/archgenpsychiatry. 2011.148

PMid: 22065253 PMCid: PMC3626112

5. Picardi A, Gigantesco A, Tarolla E, Stoppioni V, Cerbo R, Cremonte M, et al. Parental burden and its correlates in families of children with Autism Spectrum Disorder: A multicentre study with two comparison groups. Clinical Practice and Epidemiology in Mental Health 2018; 14:143-176

https://doi.org/10.2174/174501790181401 0143

PMid: 30158998 PMCid: PMC6080067

6. Hu X, Han ZR, Bai L, Gao MM. The mediating role of parenting stress in the relations between parental emotion regulation and parenting behaviours in Chinese families of children with Autism Spectrum Disorders: A dyadic analysis. Journal of Autism and Developmental Disorders 2019; 49(10): 3983-98. 
https://doi.org/10.1007/s10803-019-

04103-z

PMid: 31197635 PMCid: PMC6751273

7. Falk NH, Norris K, Quinn MG. The factors predicting stress, anxiety and depression in the parents of children with autism. Journal of Autism and Developmental Disorders 2014; 44 (12):3185-203. https://doi.org/10.1007/s10803-014-21894

PMid: 25022253

8. Zhou W, Liu D, Xiong X, Xu H. Emotional problems in mothers of autistic children and their correlation with socioeconomic status and the children's core symptoms. Medicine (Baltimore) 2019; 98 (32):e16794.

https://doi.org/10.1097/MD.00000000000 16794

PMid: 31393408 PMCid: PMC6708901

9. Lavelle TA, Weinstein MC, Newhouse JP, Munir K, Kuhlthau KA, Prosser LA. Economic burden of childhood autism spectrum disorders. Pediatrics 2014; 133(3):e520-9.

https://doi.org/10.1542/peds.2013-0763

PMid: 24515505

10. Estes A, Swain DM, MacDuffie KE. The effects of early autism intervention on parents and family adaptive functioning. Pediatric Medicine 2019; 2:21. https://doi.org/10.21037/pm.2019.05.05 PMid: 31583390 PMCid: PMC6776235

11. Jokiranta E, Brown AS, Heinimaa M, Cheslack-Postava K, Suominen A, Sourander A. Parental psychiatric disorders and autism spectrum disorders. Psychiatry Research 2013; 207(3):203-11. https://doi.org/10.1016/j.psychres.2013.01 .005

PMid: 23391634 PMCid: PMC3654001

12. Sustainable development goals [Internet] [cited 2019 Oct 28] Available from: https://sustainabledevelopment.un.org/topi cs/sustainabledevelopmentgoals

13. Khader SA, Rao SS, Kamath N. Clinical profile of children with autism spectrum disorder: A study from coastal Karnataka. Indian Journal of Public Health Research and Development 2019; 10(3): 228 - 31. https://doi.org/10.5958/09765506.2019.00 493.5

14. Leonard D. Symptom checklist 90 R Administration, scoring and procedure manual. $3^{\text {rd }}$ ed. Minneapolis: Pearson; 1992.

15. Bitsika V, Sharpley CF, Bell R. The buffering effect of resilience upon stress, anxiety and depression in parents of a child with an autism spectrum disorder. Journal of Development and Physical Disabilities 2013; 25:533-43. https://doi.org/10.1007/s10882-013-93335

16. Olsson MB, Hwang CP. Depression in mothers and fathers of children with intellectual disability. Journal of Intellectual Disability Research 2001; 45(Pt.6):535-43. https://doi.org/10.1046/j.13652788.2001.0 0372.x

PMid: 11737541

17. Hou YM, Stewart L, Iao LS, Wu CC. Parenting stress and depressive symptoms in Taiwanese mothers of young children with autism spectrum disorder: Association with children's behavioural problems. Journal of Applied Research in Intellect Disabilities 2018; 31(6):1113-21. https://doi.org/10.1111/jar.12471 PMid: 29790634

18. Miranda A, Mira A, Berenguer C, Rosello B, Baixauli I. Parenting Stress in mothers of children with autism without intellectual disability. Mediation of behavioural problems and coping strategies. Frontiers in Psychology 2019; 10:464. https://doi.org/10.3389/fpsyg.2019.00464 PMid: 30906274 PMCid: PMC6418028 